\title{
Characterization of a Spent Ru/C Catalyst after Gasification of Biomass in Supercritical Water
}

\author{
J. Wambach*, M. Schuberta, M. Döbeli ${ }^{b}$, and F. Vogel
}

\begin{abstract}
Carbon-supported ruthenium catalysts promote the gasification of aqueous organic feed with high efficiency to synthetic natural gas in supercritical water. Ruthenium metal was recently identified as the catalytically active species. ${ }^{[1]}$ Occasionally deactivation is observed. To understand the deactivation, the fresh and several spent catalyst samples were investigated by RBS, ERDA, and XPS. The data revealed a massive reduction of the ruthenium concentration in toto and especially of the surface concentration. Of importance is the almost complete disappearance of the spectral features in the valance band region. Coverage of the ruthenium clusters e.g. with a thin 'carbonaceous' layer, i.e. a kind of fouling, or structural modifications of the ruthenium clusters might be the origin. Additionally, leaching of ruthenium might contribute, but is not considered a major effect, because ruthenium was never found in the liquid effluent of the reactor. The influence of additionally detected corrosion products ( $\mathrm{Ni}, \mathrm{Cr}, \mathrm{Fe}, \mathrm{Ti})$ from the stainless steel and the titanium alloy walls seems to be small. No evidence for a deactivation by sulphur could be found.
\end{abstract}

Keywords: Carbon-supported ruthenium catalyst · Heterogeneous catalysis · Supercritical water gasification · Surface sensitive analysis · Wet biomass

\section{Introduction}

Wet (e.g. agricultural residues) and dry biomass (e.g. wood) are considered to play a major role in our future sustainable energy supply when transformed into synthetic natural gas (bio-SNG or biomethane). This is particularly interesting as it can be produced with high efficiency from almost any kind of biomass applying the proper conversion technology. Hydrothermal processing of wet biomass under supercritical water (SCW) conditions has great potential for producing biofuels and bio-chemicals from various types of biomass. ${ }^{[2,3]}$ Catalytic SCW gasification (SCWG) of liquid biomass or waste materials leads to nearly full conversion of the organic

\footnotetext{
${ }^{*}$ Correspondence: Dr. J. Wambach

Paul Scherrer Institut

General Energy Research Department

OVGA/113

$\mathrm{CH}-5232$ Villigen PSI

Tel.: +41563104266

E-mail: joerg.wambach@psi.ch

aPresent address: Karlsruher Institut für Technologie (KIT), Institute for Chemical Technology and Polymer Chemistry, D-76131 Karlsruhe, Germany

${ }^{b}$ ETH Zürich, Laboratory of Ion Beam Physics,

Schafmattstrasse $20, \mathrm{CH}-8093$ Zürich
}

matter to SNG. ${ }^{[4-7]}$ Operated in a continuous mode, it is a promising approach for producing sustainable energy, especially when salts contained in the biomass are recovered as nutrients due to their very low solubility in SCW.

The hydrothermal gasification of organic substances is carried out at temperatures near or above the critical point of pure water $\left(p_{c}=22.1 \mathrm{MPa}, \mathrm{T}_{c}=374\right.$ $\left.{ }^{\circ} \mathrm{C}\right)$. Due to its properties, SCW provides a unique environment to carry out chemical reactions, and acts simultaneously as both solvent and reactant. The organic material is converted in a single catalytic reactor over supported transition metal catalysts to methane, hydrogen and carbon dioxide. Due to low residence times and a small size of the plant, the overall efficiency is enhanced when compared to fermenters, and no residual sludge is left after gasification. However, the rather harsh conditions of the SCW process leave only few materials suitable for the high-pressure equipment and especially the catalyst. Ru-based catalysts are used for example in Fischer-Tropsch synthesis, ${ }^{[8]}$ hydrogenation reactions, ${ }^{[9-11]}$ $\mathrm{NH}_{3}$ synthesis, ${ }^{[12]}$ and $\mathrm{CO} / \mathrm{CO}_{2}$ methanation reactions. ${ }^{[13,14]}$ The methanation reaction is described as being extremely structure-sensitive and dependent strongly on the amount of the defect density such as atomic steps and kink sites. ${ }^{[15,16]}$

In this paper we report about the analysis and the observed modifications the catalyst undergoes after having gasified an aqueous solution of crude glycerol (20 wt $\%$ crude glycerol in water). ${ }^{[17]}$ We aim at obtaining an improved insight into the modification the catalyst undergoes during the reaction.

\section{Set-up and Analytical Tools}

At the Paul Scherrer Institute, a continuously operated catalytic hydrothermal gasification process for the production of SNG was developed. The process is typically operated at pressures of 25-30 MPa. Pressurized operation avoids water evaporation during heat-up. The process efficiency, defined as the heating value of the net methane produced to the heating value of the feed (dry basis), was calculated to be in the range of $60-70 \%$, and the residence time in the catalytic reactor is $<10 \mathrm{~min}$. For a detailed description see refs [18-20]. After having tested several catalysts, a commercially available ' $\mathrm{Ru}$ on activated charcoal' catalyst ${ }^{[21]}$ was found to be efficient and relatively stable against the harsh reaction conditions of SCWG. ${ }^{[5,6,18-20]}$ The support is activated carbon, derived from coconut shell, and consists of small, irregular grains (roughly $1 \times 1 \times 2 \mathrm{~mm}^{3}$ ). 2 $\mathrm{wt} \%(0.24$ at $\%)$ of $\mathrm{Ru}$ is deposited on the support as an egg-shell-type catalyst.

Our laboratory set-up is designed for a maximum feed rate of $1 \mathrm{~kg}$ wet biomass slurry per hour, and is operable with $\mathrm{T}_{\max }$ $=500{ }^{\circ} \mathrm{C}(773 \mathrm{~K})$ and $\mathrm{p}_{\max }=35 \mathrm{MPa}$. The catalytic reactor is $1.4 \mathrm{~m}$ long, and the contained spent catalyst was recovered in six 


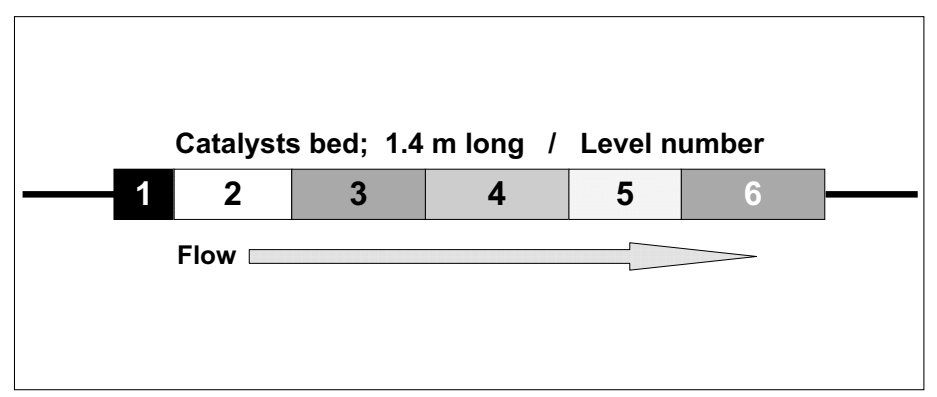

Fig. 1. The numbered boxes indicate the tentative size and position of the six fractions of the catalyst bed recovered for characterization. The labelling 'Level-1' to 'Level-6' mentioned in the text refers to these fractions.

fractions, as indicated in Fig. 1. These samples were further treated and analyzed separately. The labeling 'Level-1' to 'Level-6' mentioned throughout this paper refers to these six fractions.

For our investigations we applied several advanced analytical methods. Rutherford Backscattering Spectrometry (RBS) and Elastic Recoil Detection Analysis (ERDA) were performed at the ETHZ Laboratory for Ion Beam Physics. In RBS, a sample is bombarded with light ions $\left({ }^{4} \mathrm{He}\right)$ at an energy of a few $\mathrm{MeV}$. The light beam particles are scattered elastically upon interaction with the heavier atoms of the sample matrix and are detected at a backward angle (silicon surface barrier detector under an angle of $165^{\circ}$ ). The RBS spectrum is an overlay of the concentration profiles of all target elements exhibiting a nuclear mass greater than the projectile mass. RBS is a quantitative method because the elastic scattering cross sections are well known. ${ }^{[22]}$ The collected RBS data were simulated using the RUMP software.[23] ERDA relies on the same physical principles as RBS, but the recoiling target atoms are detected instead of the scattered projectiles. In contrast to RBS, in ERDA the sample is bombarded by a heavy ion beam under glancing incidence $\left(12 \mathrm{MeV}^{127} \mathrm{I}\right.$ beam was used under an incidence angle of $18^{\circ}$ ). The energy of the elastic forward-scattered target nuclei (recoils) is analyzed in a mass dispersive spectrometer, a combination of a time-of-flight spectrometer with a gas ionization chamber. The data were analyzed by means of the DataFurnace code. ${ }^{[24]}$ ERDA provides quantitative information on the elemental composition near the sample surface. A total area of about $3 \mathrm{~mm}^{2}$ is analyzed per spot, and the corresponding mass spectra were integrated to about 90 $\mathrm{nm}$ in depth.
X-ray Photoelectron Spectroscopy (XPS) was used for qualitative and quantitative elemental analysis of the surface ing the oxidation state of the elements, particularly of ruthenium on the catalyst. Monochromatic Al K $\alpha$ (hv = $1486.6 \mathrm{eV}$ ) radiation was used as $\mathrm{X}$-ray source in a VG Escalab 220i XL apparatus. The X-rays illuminate a small area of about $0.5 \times 0.8$ $\mathrm{mm}^{2}$. Due to the low kinetic energy of the photoelectrons the probing depth is low and the analysis covers the surface and the topit is assumed that only a few of the outer monolayers of a sample are analyzed. ${ }^{[25-27]}$ Detail scans were recorded with a pass energy $E_{\text {pass }}=20 \mathrm{eV}$. The spectra were normalized in intensity to the $\mathrm{C} 1 \mathrm{~s}$ peak, as the carbon signal from the support is the most prominent one. In case of sample charging, the spectra were shifted to match the C1s signal positioned at $284.46 \mathrm{eV}$. Dried catalyst grains were mounted on conductive carbon tapes and measured without further treatment.

Quantitative elemental analysis of the samples from the gasification studies was performed with a Spectro Ciros Inductively Coupled Plasma-Optical Emission Spectrometer (ICP-OES), which exhibits a high sensitivity and is able to detect corrosion products or potentially leached ruthenium from the catalyst. This device was calibrated with different dilutions of multielement standard solutions (purchased either from Kraft or from Merck).

The catalyst samples were also analyzed with the classical techniques for total surface area, active metal surface area, and pore volume. These data are discussed in ref. [20]. of the catalyst samples and for determinmost layers of the sample, only. Generally,

\section{Results}

Continuous gasification experiments showed that the catalyst efficiently converted model compounds like ethanol or pure glycerol without deactivation to stoichiometric amounts of $\mathrm{CH}_{4}$ and $\mathrm{CO}_{2}{ }^{[5,6,18,19]}$ However, when crude glycerol was fed, occasionally the catalyst deactivated. Analysis of the catalyst revealed a tremendous loss of specific $\mathrm{Ru}$ surface area from $3.1 \mathrm{~m}^{2} / \mathrm{g}$ (fresh) down to $0 \mathrm{~m}^{2} / \mathrm{g}$ (Level-1), $0.1 \mathrm{~m}^{2} / \mathrm{g}$ (Level-3) to $0.7 \mathrm{~m}^{2} / \mathrm{g}$ (Level-6). A comparable behavior of the pore volume was observed, too. These experimental data will be presented in detail in a separate paper. ${ }^{[20]}$

ICP-OES analysis revealed that the spent catalyst lost ruthenium, however it was still present on all catalyst samples but with inhomogeneous distribution. Table 1 compares the obtained atomic $\mathrm{Ru} / \mathrm{C}$ ratios with the results from other applied methods. Traces of corrosion products from the materials of the construction of the plant $(\mathrm{Fe}, \mathrm{Ni}, \mathrm{Cr}, \mathrm{Ti})$ were found on all spent samples.

Using ERDA, the elemental composition in the vicinity of the surface of the individual catalyst samples can be determined quantitatively. Several grains were mounted close together on a sample holder to make the sample compatible with the beam size and the glancing-incidence geometry of ERDA. This led to some averaging of the signal over a few grains, however the rough surface structure of the grains made the determination of the local concentration profiles problematic. The corresponding mass spectra were integrated to about $90 \mathrm{~nm}$ in depth, and ruthenium was well detected (Table 1).

The Level-6 samples indicate a Ru enrichment by about a factor 3 , which could be interpreted with ruthenium leaching from the entrance and redepositing towards the end of the reactor. In the liquid phase at the outlet of the plant, however, ruthenium was never detected. Corrosion products $(\mathrm{Cr}, \mathrm{Fe}, \mathrm{Ni}$, and $\mathrm{Ti})$ from the stainless steel and the titanium alloy walls were found on the spent catalyst samples in considerable amounts (Level-1: 2.5 at $\%$, Level-6: $~ 3.5$ at\%). Additionally, potassium and phosphorus, both present in crude glycerol, were detected on the spent cata-

Table 1. Ruthenium concentrations $(\mathrm{Ru} / \mathrm{C})$ determined on fresh and spent catalyst samples. - ICP-OES: performed after dissolution of the samples. RBS: data from ground samples. - Italic numbers give the relative change.

\begin{tabular}{|c|c|c|c|c|c|c|c|c|c|}
\hline $\mathrm{Ru} / \mathrm{C}$ ratio [at \%] & Manufacturer ${ }^{[22]}$ & \multirow{2}{*}{\multicolumn{2}{|c|}{$\begin{array}{c}\text { ICP-OES } \\
\text { bulk }\end{array}$}} & \multirow{2}{*}{\multicolumn{2}{|c|}{$\begin{array}{c}\text { RBS } \\
1.4 / 5.5 \mu \mathrm{m}\end{array}$}} & \multirow{2}{*}{\multicolumn{2}{|c|}{$\begin{array}{l}\text { ERDA } \\
90 \mathrm{~nm}\end{array}$}} & \multirow{2}{*}{\multicolumn{2}{|c|}{$\begin{array}{c}\text { XPS } \\
\sim 1.5 \mathrm{~nm}\end{array}$}} \\
\hline Information & 'egg shell' & & & & & & & & \\
\hline Fresh: & $0.24-0.21$ & 0.16 & 1 & 0.35 & 1 & 0.7 & 1 & 3.53 & 1 \\
\hline Level-1: & & 0.06 & 0.38 & 0.26 & 0.74 & 0.5 & 0.71 & 0.70 & 0.20 \\
\hline Level-6: & & 0.11 & 0.70 & 0.37 & 1.06 & 2.2 & 3.14 & 1.61 & 0.46 \\
\hline
\end{tabular}


lyst, but were identified not to be involved in the catalyst de-activation. ${ }^{[19,20]}$

Depth profile measurements performed on full catalyst grains were obtained by RBS analysis applying a $2 \mathrm{MeV}^{4} \mathrm{He}$ beam (analysis depth: about $1.4 \mu \mathrm{m}$ ) as well as applying a $5 \mathrm{MeV}{ }^{4} \mathrm{He}$ beam (analysis depth: about $5.5 \mu \mathrm{m}$ ) under normal-incidence. An overlay of depth profiles from fresh catalyst samples and spent catalyst samples (Level-1 and -6) is depicted in Fig. 2. The dashed lines indicate the energetic positions of oxygen and ruthenium at channel numbers about 145 and 360, respectively, (Fig. 2) and correspond to the sample surface. Towards lower energy, i.e. lower channel numbers, the scattered ions have lost energy continuously while passing through the sample, and are a measure of the depth where for the corresponding element the scattering took place. Because standard RBS probes an area in the order of about $1 \mathrm{~mm}^{2}$, surface roughness of the grains influences the shape of the measured depth profiles. Quantitative interpretation of the profiles is therefore complicated. Qualitatively, it can be stated i) that already on the fresh catalyst a certain surface enrichment with ruthenium exists, enhanced on the spent catalysts, ii) that on Level-1 catalyst de-activation is accompanied by a loss of ruthenium (see the less intense yield trace), and iii) that in all investigated samples the Ru carrying layer is thicker than the probing depth. The latter finding might be related to the rough surface structure and to the pores, large enough to be accessible during the ruthenium deposition process. Additional signals on the spent catalyst samples can be assigned to $\mathrm{Ti}, \mathrm{Cr}, \mathrm{Fe}$, and $\mathrm{Ni}$, as well as potassium. From the peak position and shape it can be concluded that all these elements are surface contaminations.

In order to overcome the influence of the surface roughness and the intrinsic inhomogeneity, ground catalyst samples were measured with RBS applying $5 \mathrm{MeV}$ He beam (Fig. 3). This led to smooth RBS curves which can be well quantified and yield ruthenium concentrations close to the bulk content of the catalyst samples (see Table 1). Additionally, signals from contaminants on the spent catalyst samples vanished proving them as surface contaminations. Again it is clearly visible that the sample from Level-1 carries a lower amount of ruthenium compared to the fresh and Level-6 samples.

XPS spectra show the prominent $\mathrm{C} 1 \mathrm{~s}$ signal of the carbon support at $284.45 \mathrm{eV}$ and additionally some less intense features (see Fig. 4, left). These signals can be associated to $\mathrm{Ru} 3 \mathrm{~d}^{5} / 2$ signals, however the corresponding $\mathrm{Ru} 3 \mathrm{~d}^{3} /$, peaks interfere with the strong $\mathrm{C} 1 \mathrm{~s}$ signal from the support. The fresh catalyst sample shows a broad feature
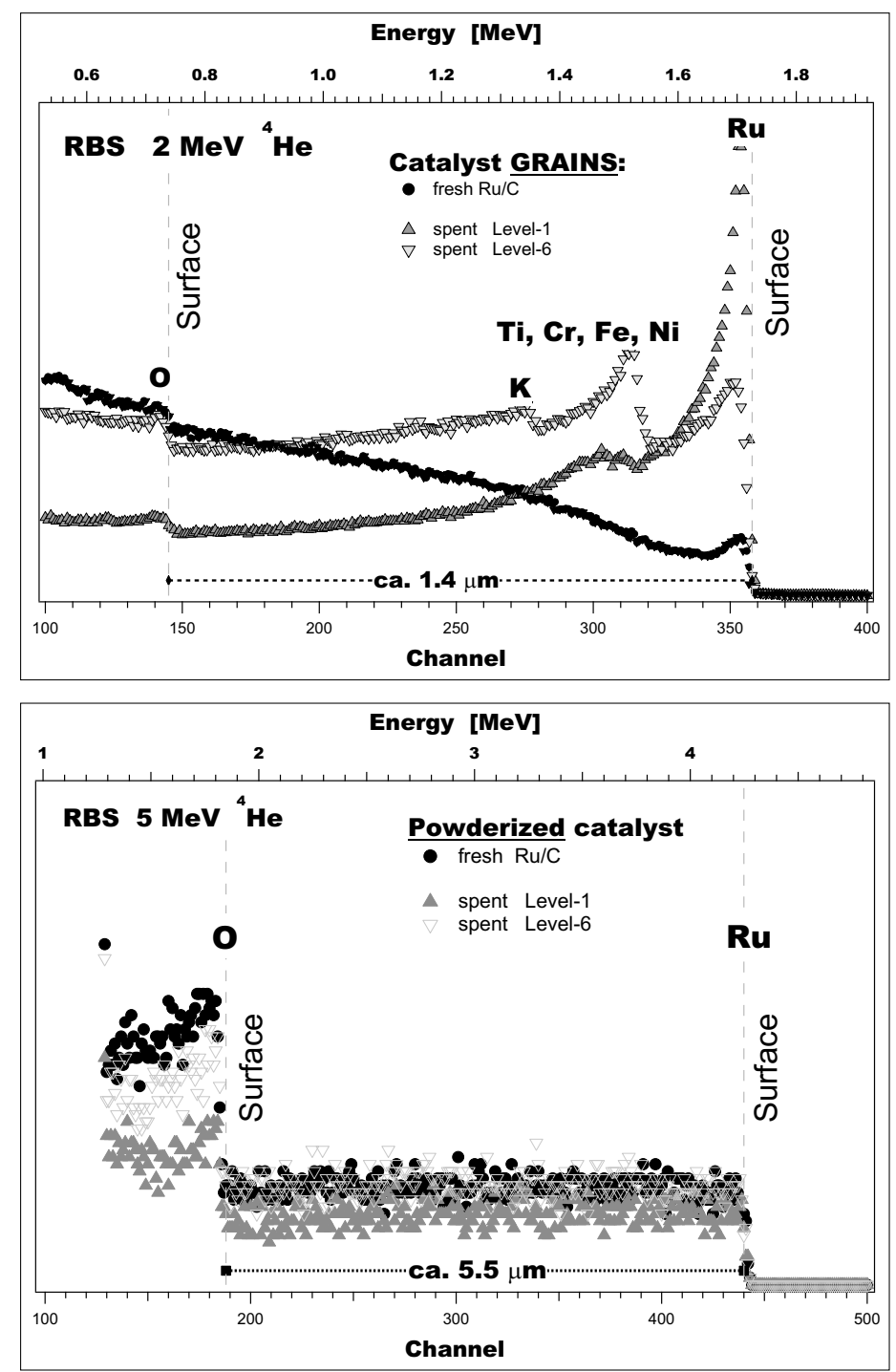

Fig. 3. Comparison of RBS depth profiles from ground catalyst to overcome surface roughness and intrinsic inhomogeneity. Analyzed: fresh catalyst sample and two spent catalyst samples (Level-1 and -6). Data taken with $5 \mathrm{MeV}{ }^{4} \mathrm{He}$ beam analysing to about $5.5 \mu \mathrm{m}$ in depth.

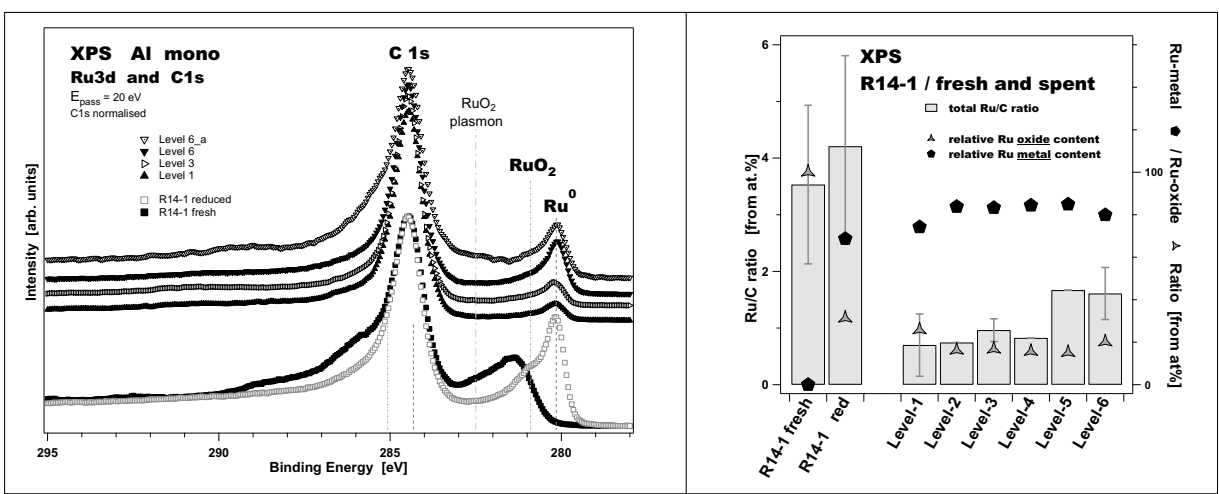

Fig. 4. Left: XP spectra showing the C1s and Ru3d region for a) fresh catalyst (bottom), b) reduced catalyst, and c) spent catalysts, Level- 1 to -6 (top). The spectra are normalised with respect to the $\mathrm{C} 1 \mathrm{~s}$ peak. The $\mathrm{Ru} 3 \mathrm{~d}^{5} /{ }_{2}$ positions of some relevant species are indicated with lines. The Ru $3 d$ signals exhibit a spin-orbit split into $3 d^{5} / 2$ and $3 d^{3} / 2$ separated by $4.17 \mathrm{eV}$. Right: Results from peak fitting showing the total $\mathrm{Ru} / \mathrm{C}$ ratio (gray bars; with error bars) and the relative Ru metal $(\bullet)$ and Ru oxide concentration $(\lambda)$.

Table 2. Determined XPS peak positions $\left(\mathrm{E}_{\mathrm{Bin}}[\mathrm{eV}]\right)$ and chemical assignment measured on the reduced, and spent $\mathrm{Ru} / \mathrm{C}$ catalyst samples using a monochromatic Al K $\alpha$ source. - ND: not determined.

\begin{tabular}{|c|c|c|c|c|}
\hline $\mathbf{R u} /$ C catalyst $/$ & $\mathbf{R u}(\mathbf{0})$ & $\mathbf{R u O}$ & plasmon & 'Ru oxide' \\
\hline $\mathbf{R u 3 p}{ }^{3} / 2$ & 461.3 & $462.1-462.7$ & $\sim 465.5$ & 463.6 \\
\hline $\mathbf{R u 3 d} 5 / 2$ & $\mathbf{2 8 0 . 0 - 2 8 0 . 2}$ & $\sim \mathbf{2 8 0 . 8}$ & $\mathbf{2 8 2 . 5}$ & $\mathbf{2 8 1 . 5}$ \\
\hline O1s & $(530.0)$ & $529.5-531.0$ & & (ND) \\
\hline
\end{tabular}


at about $281.5 \mathrm{eV}(\mathrm{Ru} \mathrm{3d} / 5)$, which might consist of several signals. A weak shoulder at about $286.0 \mathrm{eV}$ might be related to the corresponding $\mathrm{Ru} 3 \mathrm{~d}^{3} / 2$ signal (spinorbit split of about $4.2 \mathrm{eV}$ ). The reduced catalyst and the spent samples (Level-1 to -6) show a clear signal at about $280.2 \mathrm{eV}$ and a shoulder at about $280.8 \mathrm{eV}$. For each $\mathrm{Ru} 3 \mathrm{~d}^{5} / 2$ signal the corresponding $\mathrm{Ru} 3 \mathrm{p}^{3} / 2$ peak was recorded, and Table 2 summarizes the related peak positions.

The determined total $\mathrm{Ru}$ surface content, expressed as $\mathrm{Ru} / \mathrm{C}$ ratio (Fig. 4, right, grey bars) decreases drastically to about $20 \%$ on the spent samples from Level-1 to -4 , and increases again to about $50 \%$ of the initial value towards the end of the reactor (Level-5 and -6). The XPS-derived surface ruthenium concentrations are almost always higher than the $\mathrm{Ru} / \mathrm{C}$ ratios obtained with the other methods. Keeping in mind that XPS is by far more surface sensitive, ${ }^{[25-27]}$ this finding can only be explained with a surface enrichment with $\mathrm{Ru}$, supporting the RBS depth profiles shown in Fig. 2. The calculated error bars in the $\mathrm{Ru} / \mathrm{C}$ ratios are smaller for the spent catalyst samples, possibly as a consequence of some modifications of the catalyst surface during the SCWG process. The relative change of the ruthenium content is pronounced when measured with XPS (see Table 1), supporting a surface-related effect.

From our own measurements and in agreement with literature (see Table 3, ${ }^{[28-34]}$ ) the $280.2 \mathrm{eV}$ signal can be related to metallic ruthenium. This is in agreement with the detection of metallic ruthenium by in situ XAS measurements. ${ }^{[1]}$ There it was found that the originally oxidized ruthenium (e.g. $\mathrm{RuO}_{2}$ ) is reduced during the SCWG process to metallic $\mathrm{Ru}^{0}$, which is present on the catalyst as sole catalytically active species.
The finding of metallic ruthenium is further in agreement with reports on the catalytic gasification of lignin by Ketchie et al. ${ }^{[35]}$ and Yamaguchi et al. ${ }^{[36,37]}$ However, these findings are in contradiction to the report of Park and Tomiyasu, ${ }^{[38]}$ who proposed a mechanism with a redox couple $\mathrm{Ru}^{+4} / \mathrm{Ru}^{+2}$ (i.e. $\mathrm{RuO}_{2} / \mathrm{RuO}$ ) for the hydrothermal gasification over unsupported $\mathrm{RuO}_{2}$.

The shoulders/peaks recorded at higher binding energy presumably represent oxidized ruthenium. The presence of oxidic ruthenium could be supported from the analysis of the O1s spectra. However these spectra are not usable as support-related oxygen signals dominate the spectra. Literature discusses the peak position of the ruthenium dioxide, $\mathrm{RuO}_{2}$, differently (see Table 3). The majority of literature. [e.g. 31,32] and our own measurements on a reference material ${ }^{[39]}$ find binding energies of about $280.8 \mathrm{eV}$, however some ${ }^{[28-30]}$ report higher binding energies (281.4-282.0 eV). The latter values are similar to the one recorded on our fresh catalyst $(\sim 281.5 \mathrm{eV})$. For our case of the $\mathrm{Ru} / \mathrm{C}$ catalyst we assign the peak at about $280.8 \mathrm{eV}$ to $\mathrm{RuO}_{2}$, as corresponding reference samples give the same peak position and shape. The initially measured $281.5 \mathrm{eV}$ peak is likely a kind of $\mathrm{Ru}$ oxide too, however a clear identification and discrimination from the $280.8 \mathrm{eV}$ feature is not possible. The assignment of an additional weak feature at even higher binding energies (about $282.5 \mathrm{eV}$ ) is discussed controversially, too. Some literature, see Table 3, label it ' $\mathrm{RuO}_{3}$ ', however $\mathrm{RuO}_{3}$ is described not to be stable as bulk compound. ${ }^{[40,41]}$ More likely is the interpretation given by Over et al. ${ }^{[33]}$ and by Ernst and Sloof, ${ }^{[34]}$ who show that because of the conductivity of $\mathrm{RuO}_{2}$ the excitation of a plasmon leads to the observed satellite.

Peak fitting (Fig. 4, right) revealed that all spectra from the reduced or spent catalyst show primarily ruthenium in the metallic state $\left(\mathrm{Ru}^{0}\right)$, together with a weak shoulder at about $280.8 \mathrm{eV}$ indicative of $\mathrm{RuO}_{2}$ (about $20 \%$ of the corresponding total $\mathrm{Ru}$ content). The finding of small amounts of $\mathrm{RuO}_{2}$ on the spent catalyst might not necessarily be related to the SCWG process (see the in situ XAS da$\mathrm{ta}^{[1]}$ ), but could originate from oxidation of the surface of the ruthenium clusters during handling and storage in air. The $\mathrm{RuO}_{2}$ concentration did not change when re-measured even after extended times indicating that the (presumed) oxidation occurs fast. Shen et al., [28] however, observed by XPS only ruthenium signals ( $\mathrm{Ru}$ $3 \mathrm{~d}^{5} / 2$ and valence band) from the metallic state on ruthenium powder, which was firstly reduced and consecutively exposed to pure oxygen at room temperature. This might indicate that either XAS as 'bulk' method is not sensitive to a very thin oxide layer, or just to domains of $\mathrm{RuO}_{2}$ on top of an otherwise metallic ruthenium cluster. Thus the origin of that $\mathrm{RuO}_{2}$ species is speculative, and further work is needed to identify its origin. Further, in the spectrum of the spent sample 'Level-6_a' a weak shoulder at about $282.5 \mathrm{eV}$ could be assigned to the $\mathrm{RuO}_{2}$ plasmon, however a kind of ruthenium-nickel alloy cannot be excluded as a very intense $\mathrm{Ni}$-oxide signal (about six times the ruthenium content) is measured on that sample. Because Hedge et al. ${ }^{[42]}$ describe for a $\mathrm{Ni}-4.96 \mathrm{at} \% \mathrm{Ru}$ alloy a Ru3d $5 / 2$ peak position of about $279.9 \mathrm{eV}$, the assignment of the $282.5 \mathrm{eV}$ peak to be a $\mathrm{RuO}_{2}$ plasmon is more realistic.

The observed binding energy shifts could also be due to cluster-size effects of the ruthenium clusters, i.e. initial- and/ or final-state effects as described e.g. by Bagus et al. ${ }^{[43]}$ Pedersen and Lunsford ${ }^{[44]}$

Table 3. Comparison of Ru3d $5 / 2$ and Ru3p $3 / 2$ peak positions of ruthenium metal and oxides determined by XPS; literature data ${ }^{[28-34]}$ and own measurements.

\begin{tabular}{|c|c|c|c|c|c|c|c|c|c|}
\hline $\mathbf{E}_{\text {Bin }}[\mathbf{e V}]$ & \multicolumn{2}{|c|}{$\begin{array}{c}\text { Shen } \text { et al. } \\
\text { [28; see also literature therein] }\end{array}$} & \multirow{2}{*}{$\begin{array}{c}\text { Lewera } \\
\text { et al. / } \\
\text { Larichev } \\
\text { et al. }{ }^{[29,30]} \\
\text { Ru3d } 3 \mathbf{d}_{2}\end{array}$} & \multirow{2}{*}{$\begin{array}{c}\text { Kaga } e^{t} \\
\text { al. }^{[31]} \\
\text { Ru3d }^{5} / 2\end{array}$} & \multirow{2}{*}{$\begin{array}{c}\text { NIST } \\
\text { Database } \\
2^{[32]} \\
\text { Ru3d }^{5} / 2\end{array}$} & \multirow{2}{*}{$\begin{array}{l}\text { Over } e^{t} \\
\text { al. }^{[33]}\end{array}$} & \multirow{2}{*}{$\begin{array}{l}\text { Ernst + } \\
\text { Sloof }^{[34]} \\
{\operatorname{Ru} 3 p^{3} / 2}_{2}\end{array}$} & \multicolumn{2}{|c|}{$\begin{array}{c}\text { Ru reference samples / } \\
\text { this work }\end{array}$} \\
\hline & $\mathrm{Ru} 3 \mathrm{p}^{3} / 2$ & Ru3d $3{ }^{5} / 2$ & & & & & & $\operatorname{Ru} 3 d^{5} / 2$ & $\mathrm{Ru} 3 \mathrm{p}^{3} /_{2}$ \\
\hline $\operatorname{Ru}(\mathbf{0})$ & $\begin{array}{l}461.6- \\
\sim 461.8\end{array}$ & 280.2 & 280.2 & 280.0 & $\begin{array}{c}279.9- \\
280.2\end{array}$ & 280.1 & $\sim 461.5$ & $\begin{array}{c}279.9- \\
280.2\end{array}$ & $\begin{array}{c}461.3- \\
461.7\end{array}$ \\
\hline $\begin{array}{l}\operatorname{Ru}(0)+ \\
\text { ads. } \mathrm{O}_{2}\end{array}$ & 461.6 & 280.2 & & & & 281.1 & & & \\
\hline \multirow[t]{2}{*}{$\mathrm{RuO}_{2}$} & \multirow{2}{*}{$\begin{array}{c}464.9- \\
465.0\end{array}$} & \multirow{3}{*}{282.0} & 281.4 & 280.8 & $\begin{array}{c}280.6- \\
281.0\end{array}$ & 280.8 & 462.7 & $\begin{array}{c}280.7- \\
280.8\end{array}$ & 462.1 \\
\hline & & & & & 282.1 & & & & \\
\hline plasmon & & & & & & 282.7 & $\sim 467.5$ & $\sim 282.4$ & $\sim 465.5$ \\
\hline ' $\mathrm{RuO}_{3}{ }^{\prime}$ & & & 282.8 & 283.0 & $\begin{array}{c}282.5- \\
283.3\end{array}$ & & & & \\
\hline
\end{tabular}


report for ruthenium-exchanged $\mathrm{NaY}$ zeolites that in the case of supported ruthenium clusters with sizes below $1 \mathrm{~nm}$ the corresponding XPS signals for metallic ruthenium shift from $280.0 \mathrm{eV}$ to 281.0 eV. Similarly, studying Ni deposition on $\gamma-\mathrm{Al}_{2} \mathrm{O}_{3}$ a comparable shift of the Ni XPS signal was found by Loviat et al. ${ }^{[45]}$ As $\mathrm{SEM} / \mathrm{STEM}$ analysis of the $\mathrm{Ru} / \mathrm{C}$ catalyst showed ruthenium clusters in the order of $\leq 1.0 \mathrm{~nm}$ (fresh catalyst) and in the range of about 1.5 to $3.0 \mathrm{~nm}$ (spent catalyst), $[5,6,19,20]$ such an effect cannot be excluded and in fact might be the origin for the $281.5 \mathrm{eV}$ peak on the fresh catalyst, but further work is needed to confirm that assumption. Sintering of ruthenium clusters is not considered to affect the catalyst performance significantly, as Waldner et al. showed. ${ }^{[6]}$

Deactivation by sulphur can most likely be excluded, as contamination with sulphur was found only on one sample of Level-3 in very low amounts $(0.4$ at $\%)$ and never on samples of Level-1. The influence of the observed corrosion products $\left(\mathrm{Ni}: 2^{\text {nd }}\right.$ half of the reactor only / mean value $\sim 1.5$ at $\%$, Cr: all levels / 0.3at $\%$, Fe: $1^{\text {st }}$ half / 0.28at\%, Ti: $1^{\text {st }}$ half / $~ 0.25$ at $\%$ ) is not fully understood, but our observations during the process ${ }^{[20]}$ indicate the influence of nickel and chromium on the catalytic reaction to be small or even negligible.

The XP valence band (VB) spectra in Fig. 5 compare the spectra from the pure carbon support (white circles), the fresh (black squares) and reduced (grey squares) catalyst samples with the spent catalyst samples. The spectra are normalized with respect to the carbon $\mathrm{C} 1 \mathrm{~s}$ intensity and peak position. For an assignment, lines indicating the peak positions and relative intensities of metallic ruthenium and $\mathrm{RuO}_{2}$ as reported in literature are given. Blume $^{[46]}$ reports $\mathrm{VB}$ emission lines of a cleaned $\mathrm{Ru}(0001)$ to be at 5.0, 2.6, and $0.3 \mathrm{eV}$ measured in an UPS study. Riga et al. ${ }^{[47]}$ measured pressed pellets of $\mathrm{RuO}_{2}$ with XPS. They report VB structures to be located at 6.9, 4.7, and $0.6 \mathrm{eV}$. Using nonmonochromatic $\mathrm{Mg} \mathrm{K} \alpha$ radiation, Shen et al. ${ }^{[28]}$ measured for metallic ruthenium peak positions at $4.8,2.8$, and $1.4 \mathrm{eV}$, and for oxidized ruthenium at 8.0, 5.5, 3.0, and $1.4 \mathrm{eV}$, which exhibits a similar VB spectrum as reported by Riga or the one measured in this work. Thus the spectra of the fresh and the reduced catalysts are in good agreement with $\mathrm{RuO}_{2}$ (fresh catalyst) and ruthenium metal (reduced catalyst), supporting the Ru3d peak assignment discussed above.

Remarkably, the spent catalyst samples from Level-1 and -3 show almost no ruthenium-related spectral features and valence band anymore. The spectra resemble the VB of the pure carbon support (bottom spectrum). It is understandable that the

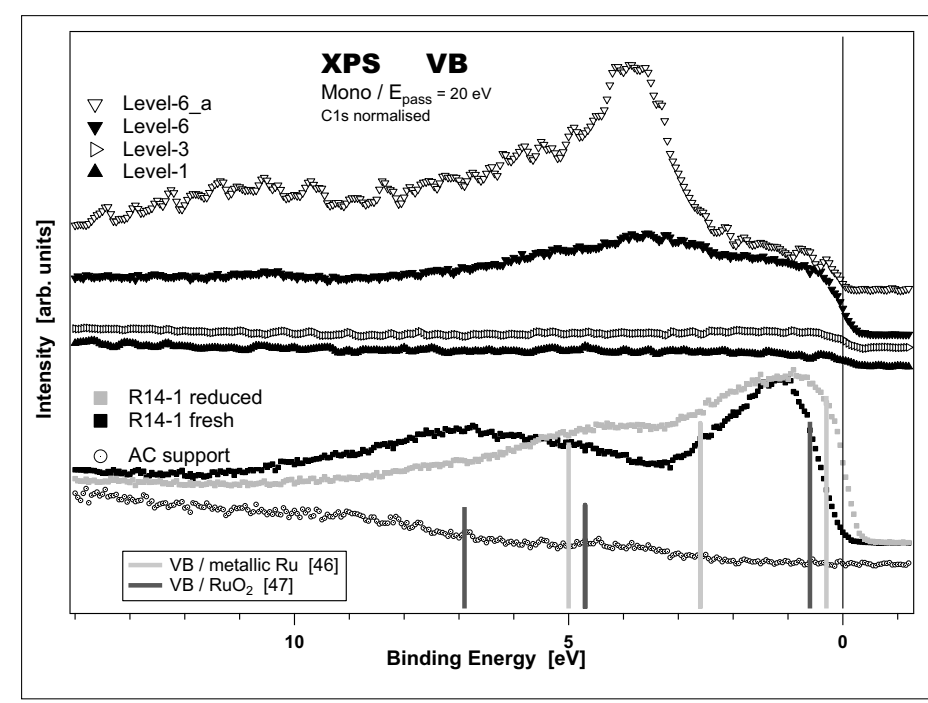

Fig. 5. XP Valence Band spectra using a monochromatic $\mathrm{Al}$ K $\alpha$ source showing from bottom to top: a) pure carbon support, b) fresh catalyst, c) reduced catalyst. Top: the spent catalyst: Level-1, -3, -6, and -6_a (massively Ni contaminated). The intensity is normalised with respect to the C1s peak. The lines give the peak positions and relative intensities of metallic ruthenium and $\mathrm{RuO}_{2} \cdot{ }^{[46,47]}$

catalyst in these parts of the reactor was de-activated. The two spectra from Level-6 possess a somewhat better developed VB, but the intensity at the Fermi level is not even $50 \%$ compared to the fresh and reduced samples, and the relative peak intensities seem to be different, too, when compared with the reduced sample. A plausible reason for the disappearance of the spectral features cannot be given at the moment. Covering the ruthenium clusters e.g. with a thin 'carbonaceous' layer, i.e. a kind of fouling, or any kind of structural modification of the ruthenium cluster might be the origin, but further work is needed to fully explain that behavior. In the topmost spectrum (Level-6_a), relatively intense, additional signals are visible, which are most likely connected with the also measured, very intense $\mathrm{Ni} 2 \mathrm{p}^{3} / 2$ signals $(\mathrm{Ni} /$ $\mathrm{Ru}=6.5$ ), and originate from a massive contamination with corrosion products on this sample.

\section{Conclusions}

The applied commercial carbon-supported ruthenium catalyst converts the aqueous organic feed very well to SNG. Occasionally, deactivation of the catalyst was observed. Supporting previous in situ XAS measurements, ${ }^{[1]}$ primarily ruthenium metal was found in ex situ XPS analysis on the spent catalyst and is confirmed as catalytically active species. The additional finding of some $\mathrm{RuO}_{2}$ on the spent catalyst samples is not understood. The commercial catalyst exhibits a broad distribution of ruthenium coverage, which might be related to the rough surface structure and to the existence of natural pores. As a consequence of the SCWG process, the total ruthenium surface concentration is lowered dramatically accompanied by a strong surface enrichment with ruthenium. As XPS analyses the outermost monolayers of a sample, and RBS/ERDA integrates the sample many monolayers deep, the difference in the relative change (see Table 1) is remarkable. It seems to be a hint for fouling, i.e. covering of some of the ruthenium clusters possibly with a 'carbonaceous' layer. Deactivation by sulphur or corrosion products $(\mathrm{Ni}, \mathrm{Cr}, \mathrm{Fe}, \mathrm{Ti})$ can most likely be excluded, however their influence is not finally understood. Leaching of ruthenium might happen, however ruthenium was never found in the liquid effluent. Sintering of ruthenium clusters was observed, but only to a limited extent, which apparently does not significantly affect the catalyst performance.

\section{Acknowledgements}

The authors are very grateful to Sousan Abolhassani-Dadras (HR-TEM; PSI), Erich De Boni and Wolfgang Märkle (SEM/EDX; PSI), and Eszter Barthazy (HAADF-STEM/ EDX; ETHZ) for having patiently measured our samples, and Alexander Wokaun for the fruitful discussions.

This investigation was financially supported by Axpo Naturstrom Fonds within the framework of the Competence Centre Energy and Mobility, CCEM-CH.

Received: August 9, 2012

[1] S. Rabe, M. Nachtegaal, T. Ulrich, F. Vogel, Angew. Chem. Int. Ed. 2010, 49, 1.

[2] D. Elliott, Biofuels Bioproducts \& Biorefining 2008, 2, 254.

[3] A. A. Peterson, F. Vogel, R. P. Lachance, M. Fröling, M. J. Antal, Jr., J. W. Tester, Energy Environ. Sci. 2008, 1, 32.

[4] S. Stucki, F. Vogel, C. Ludwig, A. G. Haiduc, M. Brandenberger, Energy Environ. Sci. 2009, 2, 535 .

[5] M. Waldner, F. Vogel, Ind. Eng. Chem. Res. 2005, 44, 4543.

[6] M. H. Waldner, F. Krumeich, F. Vogel, J. Supercrit. Fluids 2007, 43, 91.

[7] A. G. Haiduc, M. Brandenberger, S. Suquet, F. Vogel, R. Bernier-Latmani, C. Ludwig, J. Appl. Phycol. 2009, 21, 529.

[8] H. Abrevaya, M. J. Cohn, W. M. Targos, H. J. Robota, Catal. Lett. 1990, 7, 183. 
[9] A. W. Heinen, J. A. Peters, H. van Bekkum, Carbohydr. Res. 2000, 328, 449.

[10] V. A. S. Herrera, O. Oladele, K. Kordás, K. Eränen, J.-P. Mikkola, D. Y. Murzina, T. Salmia, J. Chem. Technol. Biotechnol. 2011, 86, 658.

[11] W. Wang, H. Liu, T. Wu, P. Zhang, G. Ding, S. Liang, T. Jiang, B. Han, J. Mol. Catal. A: Chem. 2012, 355,174

[12] F. Rosowski, O. Hinrichsen, M. Muhler, G. Ertl, Catal. Lett. 1996, 36, 229.

[13] R. A. Dalla'Betta, M. Shelef, J. Catal. 1977, 48, 111.

[14] Z. Kowalczyk, K. Stołecki, W. Rarog-Pilecka, E. Miskiewicz, E. Wilczkowska, Z. Karpinski, Appl. Catal. A: General 2008, 342, 35.

[15] S. B. Vendelbo, M. Johansson, J. H. Nielsen, I. Chorkendorff, Phys. Chem. Chem. Phys. 2011, $13,4486$.

[16] J. R. Rostrup-Nielsen, K. Pedersen, J. Sehested, Appl. Catal. A: General 2007, 330, 134.

[17] Crude glycerol is a co-product from the production of biodiesel. Its composition depends on the plant oil used, the trans-esterification process, and the downstream processing. The crude glycerol used in our study consisted of about 30\% glycerol, methanol, and fatty acids including their potassium salts, fatty acid esters about $10 \%$ water, and $c a$. $6 \%$ inorganic compounds.

[18] F. Vogel, 'Catalytic Conversion of HighMoisture Biomass to Synthetic Natural Gas in Supercritical Water', in 'Handbook of Green Chemistry', Vol. 2: 'Heterogeneous Catalysis', Ed. R. H. Crabtree, WILEY-VCH Verlag GmbH \& Co. KGaA, Weinheim, 2009.
[19] M. Schubert, Ph.D. thesis, ETH Zurich, No. 19039, 2010

[20] J. Wambach, M. Schubert, F. Vogel, in preparation.

[21] Engelhard-BASF.

[22] 'Handbook of Modern Ion Beam Materials Analysis', Eds. Y. Wang, M. Nastasi, Materials Research Society, 2010.

[23] L. Doolittle, Nucl. Instrum. Methods Phys. Res., Sect. B 1986, 15, 227.

[24] N. Barradas, C. Jeynes, R. Webb, Appl. Phys. Lett. 1997, 71, 291.

[25] E. Taglauer, in 'Handbook of Heterogeneous Catalysis', 2 $2^{\text {nd }}$ Edition; Eds. G. Ertl, H. Knözinger, F. Schüth, J. Weitkamp, Wiley-VCH Verlag, Weinheim, 2008.

[26] C. J. Powell, A. Jablonski, A. Naumkin, A. Kraut-Vass, J. M. Conny, J. R. Rumble Jr, J. Electron Spectrosc. Relat. Phenom. 2001, 114116, 1097.

[27] C. J. Powell, A. Jablonski, NIST Electron Effective-Attenuation Length Database Version 1.0, National Institute of Standards and Technology, Gaithersburg, MD, 2001.

[28] J. Y. Shen, A. Adnot, S. Kaliaguine, Appl. Surf. Sci. 1991, 51, 47.

[29] A. Lewera, W. P. Zhou, C. Vericat, J. H. Chung, R. Haasch, A. Wieckowski, P. S. Bagus, Electrochim. Acta 2006, 51, 3950.

[30] Y. V. Larichev, S. E. Malykhin, Kinet. Catal. 2008, 49, 581.

[31] Y. Kaga, Y. Abe, H. Yanagisawa, H. Yanagisawa, Surf. Sci. Spectra 1999, 6, 68.
[32] NIST X-ray Photoelectron Spectroscopy Database, Version 3.5, National Institute of Standards and Technology, Gaithersburg, 2003; http://srdata.nist.gov/xps/.

[33] H. Over, A. P. Seitsonen, E. Lundgren, M. Smedh, J. N. Andersen, Surf. Sci. 2002, 504, L196.

[34] M. A. Ernst, W. G. Sloof, Surf. Interface Anal. 2008, 40, 334.

[35] W. C. Ketchie, E. P. Maris, R. J. Davis, Chem. Mat. 2007, 19, 3406

[36] A. Yamaguchi, N. Hiyoshi, O. Sato, M. Osada, M. Shirai, Energy Fuels 2008, 22, 1485.

[37] A. Yamaguchi, N. Hiyoshi, O. Sato, M. Osada, M. Shirai, Catal. Lett. 2008, 122, 188.

[38] K. Park, H. Tomiyasu, Chem. Comm. 2003, 6 , 694.

[39] Sigma Aldrich, 99.9\%.

[40] E. A. Seddon, K. R. Seddon, 'Chemistry of Ruthenium', Elsevier, Amsterdam, 1984.

[41] C. Mun, L. Cantrel, C. Madic, Nucl. Technol. 2006, 156, 332.

[42] M. S. Hedge, T. S. Sampath Kumar, R. M. Mallya, Surf. Sci. 1987, 188, 255.

[43] P. S. Bagus, A. Wieckowski, H. Freund, Comput. Theor. Chem. 2012, 987, 22.

[44] L. A. Pedersen, J. H. Lunsford, J. Catal. 1980 61,39 .

[45] F. Loviat, I. Czekaj, J. Wambach, A. Wokaun, Surf. Sci. 2009, 603, 2210.

[46] R. Blume, PhD, Humboldt-Uni., Berlin, 2005.

[47] J. Riga, C. Tenret-Noel, J. J. Pireaux, R. Caudano, J. J. Verbist, Y. Gobillon, Phys. Scr. $\mathbf{1 9 7 7}, 16,351$ 